\title{
A Study on COVID-19 Vaccine Hesitancy in Bhopal
}

\author{
Keerthana S ${ }^{1}$, Mugdha Kamble ${ }^{2}$, Neeraj Khare ${ }^{3}$, Manju Toppo ${ }^{4}$ \\ ${ }^{1}$ Second Year PG Resident, ${ }^{2}$ Second Year PG Resident, ${ }^{3}$ Assistant Professor, ${ }^{4}$ Associate Professor, \\ ${ }^{1,2,4}$ Department of Community Medicine, Gandhi Medical College, Bhopal. \\ ${ }^{3}$ Govt. Medical College, Vidisha, Madhya Pradesh. \\ Corresponding Author: Manju Toppo
}

DOI: https://doi.org/10.52403/ijhsr.20220116

\begin{abstract}
Background: The coronavirus has become a global pandemic and to overcome the pandemic crisis vaccine were launched in India. COVID-19 mass immunisation has emerged as a crucial preventive technique. COVID-19 vaccine hesitancy may become a distinctive element of the pandemic's next stage. The loss of public trust in vaccines around the world is a source of concern and a serious problem for public health professionals. A study was therefore planned in Bhopal to determine whether hesitancy is present in a population and to distinguish hesitancy from other reasons why adults do not get vaccinated. The study was conducted with the objective as to assess the vaccine hesitancy in Bhopal.

Methodology: This is a cross-sectional study conducted among the general population of Bhopal during the time period between 2oth Jan to Feb 2021. 381 participants were administered with a predesigned pretested questionnaire.

Results: The mean age of the participants was 33.8 years. Majority was unskilled workers, Hindu by religion and most of them were married. $57.3 \%$ showed hesitancy for COVID vaccination. Majority had the knowledge of vaccine. Television was the major source of information. Almost $80 \%$ responded as they would continue practicing personal protective measures even after vaccination. The major reasons for hesitancy were lack of information, safety about vaccination, and side effects from the same. The public demands the proper information about the vaccine and educate the general public and communicate the important information regarding vaccinations.

Conclusion: Routine monitoring of vaccine hesitancy plays a valuable role in identifying early vaccine concerns. And adopt the strategies to address these concerns, through in-depth understanding of the nature of hesitancy, as well as who is hesitating. Given the dynamic and changing nature of vaccine hesitancy, the importance of ongoing monitoring cannot be overstated.
\end{abstract}

Key words: COVID-19, COVID-19 Vaccine, SARS-COV2 vaccine, Vaccine hesitancy, Vaccine resistance, Vaccine opposition

\section{INTRODUCTION}

As of May 18, 2021, the corona virus disease 2019 (COVID-19) has become a global pandemic, with 162 million confirmed cases and 3.4 million deaths globally. Vaccines against COVID-19 were launched in India on January 16, 2021, and were subsequently ramped up in response to an increase in cases beginning in April 2021. A tremendous humanitarian catastrophe has erupted in India as a result of the second wave of pandemics, which has resulted in an unprecedented number of hospitalizations and deaths. COVID-19 mass immunisation has emerged as a crucial preventive technique. (1)

Vaccines are one of the most important medical breakthroughs of all time, resulting in a significant reduction in the occurrence of diseases that have long afflicted humanity. Despite the fact that COVID-19 vaccines were first scarce, there 
was a huge public demand for them, and as production and availability increased, supply is meeting and eventually exceeding demand. When that time comes, COVID-19 vaccine hesitancy may become a distinctive element of the pandemic's next stage. (2)

The loss of public trust in vaccines around the world is a source of concern and a serious problem for public health professionals. Researchers used to refer to the problem as "vaccine resistance" or "vaccine opposition," but these terms have since been dropped in favour of a new phrase, "vaccine hesitancy," which has replaced the earlier terms to explain the aversion to vaccination. Vaccine hesitancy, according to the World Health Organization's (WHO) Strategic Advisory Group of Experts (SAGE) Vaccine Hesitancy working group, is defined as a delay in accepting or refusing vaccines despite availability of vaccine services.

The WHO Strategic Advisory Group of Experts on Immunization (SAGE) identified the various reasons for vaccination hesitancy, and the following definition of vaccine hesitancy was developed: "Vaccine hesitancy refers to a delay in accepting or refusing immunisation despite vaccination services being available." Vaccine apprehension is complicated and context-dependent, altering by time, place, and vaccine. Complacency, convenience, and confidence are all characteristics that influence it." (5) Vaccine complacency is known to exist in situations where the risk of vaccine-preventable diseases is minimal and immunisation is not deemed necessary. Vaccine reluctance has been found to be influenced by a lack of trust in the vaccine's safety and efficacy, as well as concerns about the health system's trustworthiness and competency. (3)

The trust of health experts, government, or public health institutions, as well as their inter-relationship, is used to make vaccination decisions. The public relies on the government and public health authorities' integrity, competence, and faith in them to prescribe appropriate vaccines that are efficacious, uncontaminated, and can be delivered safely, hence these connections are critical in vaccine uptake. (3) While vaccination is widely accepted in most populations around the world, a tiny percentage of people oppose some vaccines but accept others, while others delay or refuse vaccination because they are unsure. As a result, hesitancy is defined as a spectrum ranging from total acceptance of all vaccines to complete refusal of all vaccines. While acknowledging that hesitant persons include a wide variety of people, they differ from the small fraction of people who refuse all immunizations and have no reservations about doing so. (4)

Hesitancy is a vaccine- and contextspecific behavioral phenomena that is measured against the expectation of achieving a specified vaccination coverage goal given the immunization services available. Vaccine hesitancy may exist in situations where vaccination uptake is low due to system failures, such as stock-outs, limited availability of vaccination services (time, place, etc.), or curtailment of vaccine services in the event of conflict or natural disaster, but hesitancy is not the primary cause of unvaccinated or under-vaccinated members of the population in these situations. A study was therefore planned in Bhopal to determine whether hesitancy is present in a population and to distinguish hesitancy from other reasons why adults do not get vaccinated.

\section{Objectives}

To assess the vaccine hesitancy in Bhopal.

\section{METHODOLOGY}

Study Design: Cross-sectional study

Study Area: General population of Bhopal

Study period: $20^{\text {th }}$ Jan - Feb 2021

Sample size: 381 (With 45\% vaccine hesitancy prevalence (10), 5\% allowable error, and $95 \%$ confidence interval, the sample size is calculated as 381)

Study tool: A predesigned pretested questionnaire 
Inclusion Criteria: Those who are willing to consent for the study.

Exclusion Criteria: Those who are not willing to consent for the study.

\section{OBSERVATIONS AND DISCUSSION}

Table 1: Socio-demographic details of the study participants $(\mathbf{n}=381)$

\begin{tabular}{|c|c|c|c|}
\hline Variables & Category & $\begin{array}{l}\text { Frequency } \\
(n=381)\end{array}$ & $\begin{array}{l}\text { Percentage } \\
\text { (\%) }\end{array}$ \\
\hline \multirow{6}{*}{$\begin{array}{ll}\text { Age } & \text { (in } \\
\text { years) }\end{array}$} & $11-20$ & 41 & 10.8 \\
\hline & $21-30$ & 139 & 36.5 \\
\hline & $31-40$ & 104 & 27.3 \\
\hline & $41-50$ & 68 & 17.8 \\
\hline & $51-60$ & 22 & 5.8 \\
\hline & $>61$ & 7 & 1.8 \\
\hline \multirow[t]{2}{*}{ Gender } & Male & 259 & 68.0 \\
\hline & Female & 122 & 32.0 \\
\hline \multirow[t]{6}{*}{ Education } & Illiterate & 52 & 13.6 \\
\hline & Middle school & 61 & 16.0 \\
\hline & $\begin{array}{l}\text { Secondary } \\
\text { school }\end{array}$ & 81 & 21.3 \\
\hline & $\begin{array}{l}\text { High } \\
\text { secondary }\end{array}$ & 54 & 14.2 \\
\hline & Graduate & 104 & 27.3 \\
\hline & Postgraduate & 29 & 7.6 \\
\hline \multirow[t]{5}{*}{ Occupation } & Unemployed & 82 & 21.5 \\
\hline & Unskilled & 126 & 33.1 \\
\hline & Skilled & 49 & 12.9 \\
\hline & Govt. job & 34 & 8.9 \\
\hline & Private job & 90 & 23.6 \\
\hline \multirow[t]{3}{*}{ Religion } & Hindu & 303 & 79.5 \\
\hline & Muslim & 70 & 18.4 \\
\hline & Others & 8 & 2.1 \\
\hline \multirow[t]{2}{*}{ Area type } & Urban & 129 & 33.9 \\
\hline & Rural & 252 & 66.1 \\
\hline \multirow{2}{*}{$\begin{array}{l}\text { Marital } \\
\text { status }\end{array}$} & Married & 261 & 68.5 \\
\hline & Unmarried & 120 & 31.5 \\
\hline
\end{tabular}

The mean age \pm SD of the participants is 33.8 years $\pm 11.37,36.5 \%$ from the range of 21-30 years followed by $31-40$ years $(27.3 \%)$ and comprising $68 \%$ male and $32 \%$ female. $27.3 \%$ of the participants were graduates and followed by Secondary schooling (21.3), 33\% were in unskilled jobs, and followed by private jobs $(23.6 \%)$. The majority of the study participants were Hindu by religion (79.5\%), followed by Muslim (18.4\%) and others were $2.1 \%$ which includes Sikh, Jain, and Buddhist. 33.9\% from urban and 66.1\% from rural. Most of them were married (68.5\%) and 31.5\% were unmarried.

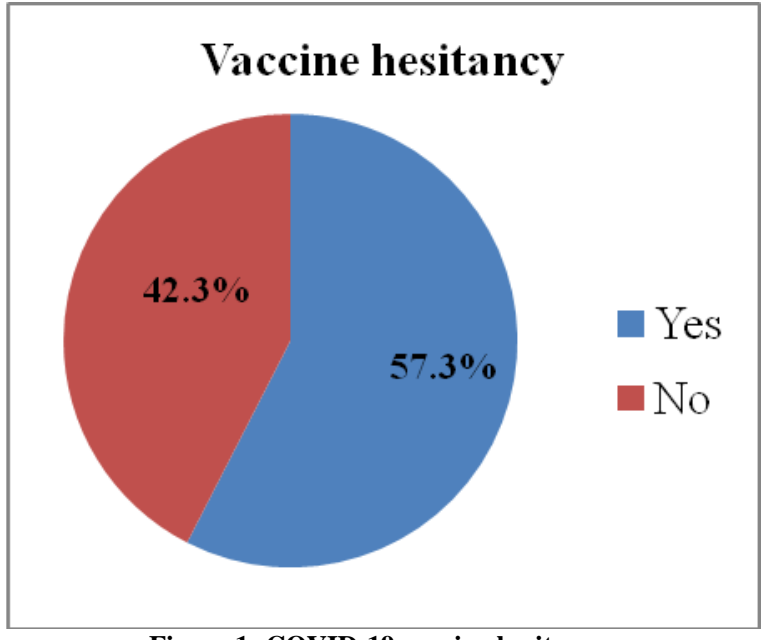

Figure 1: COVID-19 vaccine hesitancy

Among the study participants, $57.3 \%$ are hesitant to take the COVID-19 vaccine whereas $42.3 \%$ were ready to get vaccinated against COVID-19.

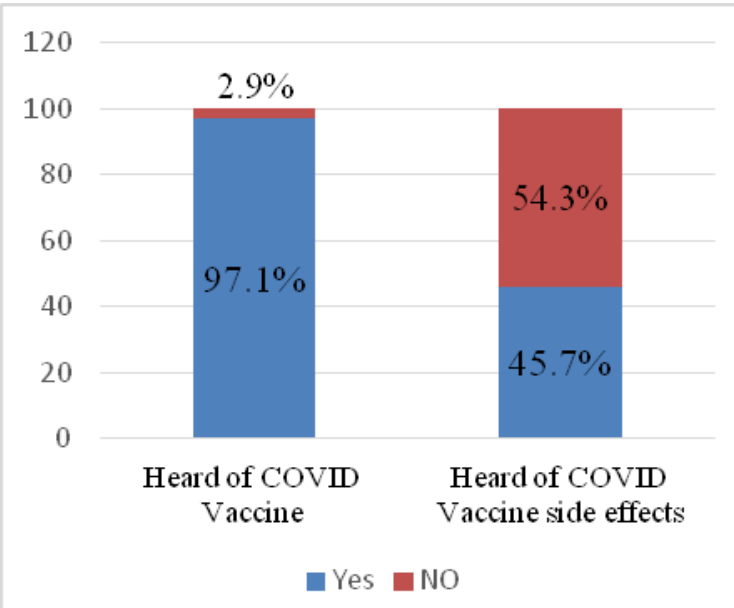

Figure 2: Knowledge of respondents about COVID-19 vaccine

Above figure 2 depicts that $97.1 \%$ of the respondents had heard about the COVID vaccine, and almost $45.7 \%$ of them heard about the side effects of COVID vaccines.

Table 2: Perceived benefits of COVID-19 vaccine
\begin{tabular}{|l|l|l|}
\hline Variables & $\begin{array}{l}\text { Frequency } \\
\text { (n=381) }\end{array}$ & $\begin{array}{l}\text { Percentage } \\
\text { (\%) }\end{array}$ \\
\hline $\begin{array}{l}\text { Vaccine provides lifelong } \\
\text { immunity }\end{array}$ & 193 & 50.7 \\
\hline $\begin{array}{l}\text { Personal protective measures } \\
\text { after Vaccination }\end{array}$ & 304 & 79.8 \\
\hline $\begin{array}{l}\text { Vaccine enough protection } \\
\text { against COVID-19 }\end{array}$ & 159 & 41.7 \\
\hline $\begin{array}{l}\text { Willing to take the vaccine if } \\
\text { freely supplied }\end{array}$ & 315 & 82.7 \\
\hline
\end{tabular}

Among the study participants, $97.1 \%$ heard of COVID-19 vaccines. And 45\% 
heard of side effects from vaccination. $50.7 \%$ of study participants responded that vaccine provides lifelong immunity, $79.8 \%$ responded that they will continue using personal protective measures like wearing a facemask, hand sanitizing, and practicing social distancing. $41.7 \%$ responded the vaccine provides enough protection against COVID-19 infection.

Among the participants, $82.7 \%$ answered that they are willing to take vaccines if freely supplied by Government. (Table 2)

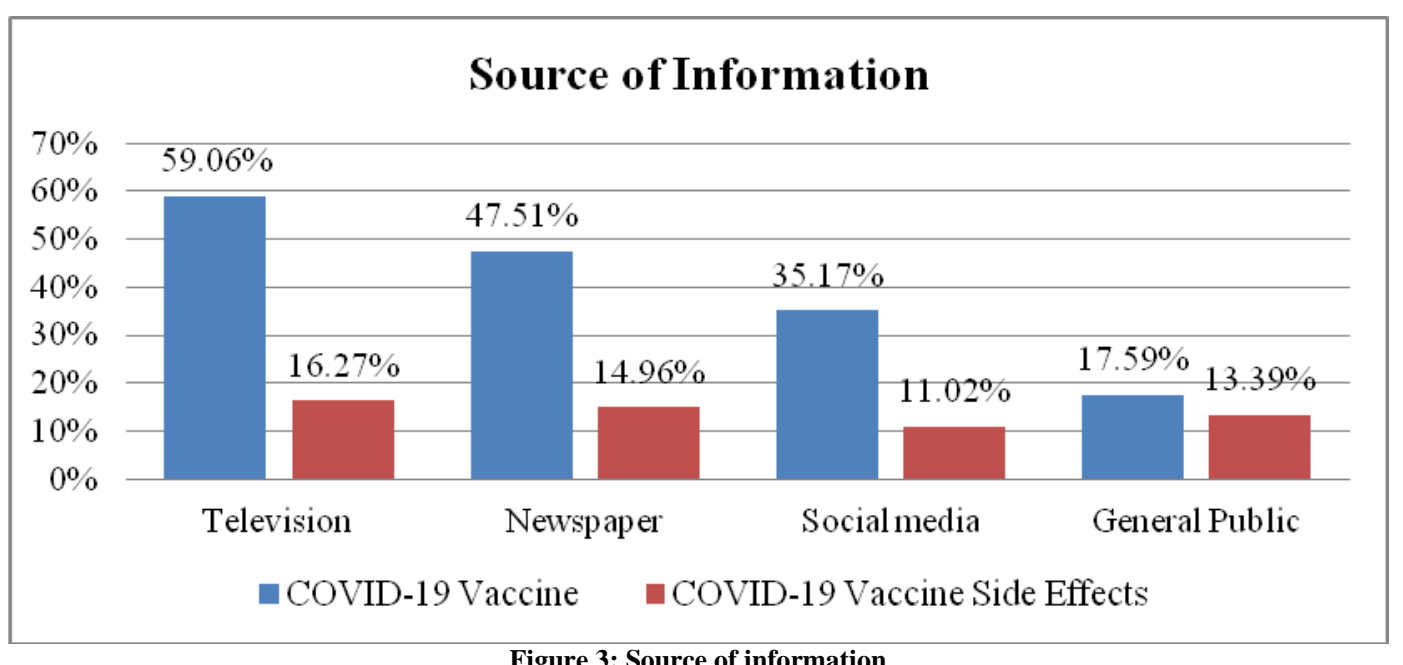

Figure 3: Source of information

In Figure 3, the source of information of COVID-19 vaccine and side effects has been depicted. The major source of information was found to be television (59.06\%) for the COVID-19 vaccine and followed by newspapers (47.51\%). The source of information for COVID-19 vaccine side effects was found to be television (16.27\%) followed by the newspaper (14.96\%).

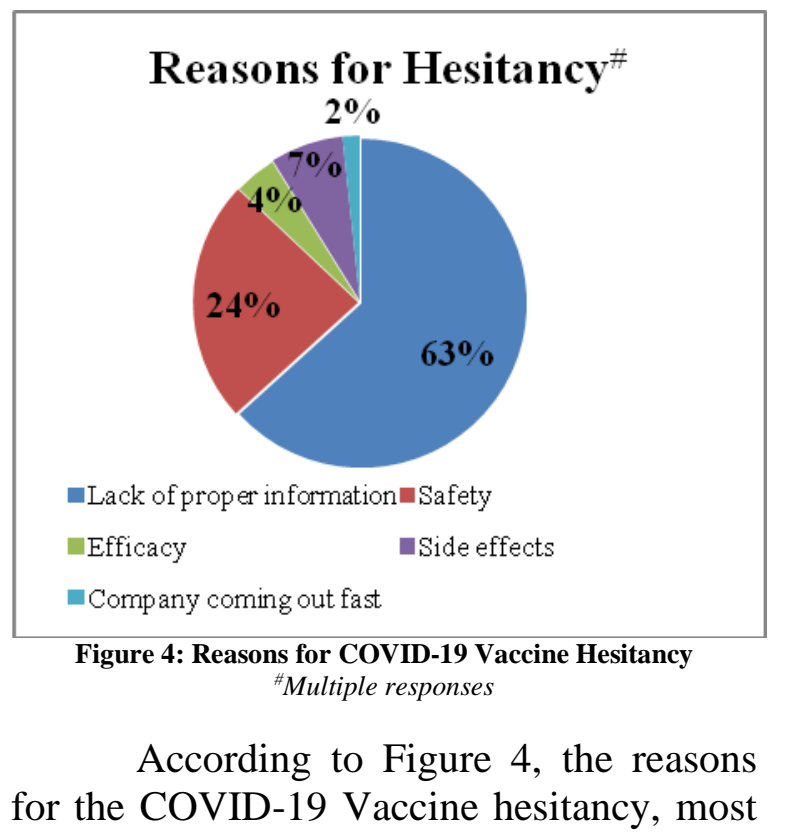

of the respondents i.e., 63\% acknowledged lack of proper information as the main reason, followed by the safety of the COVID vaccine (24\%), followed by Side effects from the COVID vaccine (7\%), followed by Efficacy of the COVID vaccine (4\%) and lastly the reason with the company coming out fast into the market (2\%).

Vaccine hesitations are an important and possibly growing problem. Vaccination hesitation rates are also associated with the periods in which studies are conducted. Similar studies have been conducted in the first three months after the pandemic announcement, stated that would not be vaccinated against SARS-CoV-2 ranged from $14 \%$ to $26 \%$. $(8,9)$

Table 3: Public opinion concerning COVID vaccine regarding Government undertaking

\begin{tabular}{|l|l|l|}
\hline Public opinions & $\begin{array}{l}\text { Frequency } \\
\text { \# }\end{array}$ & $\begin{array}{l}\text { Percentage } \\
\text { (\%) }\end{array}$ \\
\hline $\begin{array}{l}\text { Information, Education, and } \\
\text { Communication }\end{array}$ & 231 & 60.62 \\
\hline Outcome of Vaccination programs & 52 & 13.64 \\
\hline Should provide free vaccine & 49 & 12.86 \\
\hline Camps \& Booths & 40 & 10.50 \\
\hline Ban Public gathering & 38 & 9.97 \\
\hline Should open to all class of people & 29 & 7.61 \\
\hline Monetary incentive & 24 & 6.30 \\
\hline Priority to politicians & 20 & 5.25 \\
\hline Should enforce strict law regulations & 19 & 4.99 \\
\hline \multicolumn{2}{|c|}{${ }^{2}$ Multiple responses } \\
\hline
\end{tabular}


Above table projects the various public opinions to be undertaken by the Government concerning COVID vaccine. The public demands the proper information regarding the COVID vaccine schedules, time, mode of administration, place of administration, who should take the vaccine. $12.86 \%$ responded that vaccines should be freely available to the community. The public also opined to organize the camps and booths and to prevent the public gatherings. Few responses were to prioritize the politicians and to open for all classes of people. Government should enforce strict law regulations for maintaining COVID prevention protocols. The outcome of the vaccination program was not clear to the common people (13.64\%). Some of the respondents wished for monetary incentives after vaccination.

Studies have shown that higher trust in the health system was associated with the use of preventive health services such as vaccination. In order to minimize vaccine hesitancy, health authorities need to build trust in the public through the transparent management of vaccine development stages and the production and effectiveness of the SARS-COV2 vaccine. (6)

\section{CONCLUSION}

Routine monitoring of vaccine hesitancy plays a valuable role in identifying early vaccine concerns. And adopt the strategies to address these concerns, through in-depth understanding of the nature of hesitancy, as well as who is hesitating. Given the dynamic and changing nature of vaccine hesitancy, the significance of ongoing monitoring cannot be exaggerated. A survey that reveals little hesitancy this year may have a different result next year. These trends need monitoring. Exposure to inaccurate news about the disease on social media has increased the anxiety and risk perception in society with inadequate information and uncertainty.

Hence Government should come forward with sufficient IEC to demystify the myth in relate to COVID vaccine. Individuals should be encouraged to get vaccinated for both to collaborate on COVID-19 control measures and to accomplish both community and individual health responsibilities. Clear and consistent communication by government officials in a vaccination programme to be conducted here is crucial to establishing public trust in vaccination programmes and developing positive health behavior.

Acknowledgement: None

\section{Conflict of Interest: None}

\section{Source of Funding: None}

\section{Ethical Approval: Approved}

\section{REFERENCES}

1. Jain J, Saurabh S, Kumar P, Verma MK, Goel AD, Gupta MK, Bhardwaj P, Raghav PR (2021). COVID-19 vaccine hesitancy among medical students in India. Epidemiology and Infection 149, e132, 110.

https://doi.org/10.1017/S095026882100120 5

2. Trogen B, Pirofski LA. Understanding vaccine hesitancy in COVID-19. Med (N Y). 2021;2(5):498-501. doi:10.1016/j.medj.2021.04.002

3. Kumar D, Chandra R, Mathur M, Samdariya S, Kapoor N. Vaccine hesitancy: understanding better to address better. Israel journal of health policy research. 2016 Dec;5(1):1-8.

4. MacDonald NE. Vaccine hesitancy: Definition, scope and determinants. Vaccine. 2015 Aug 14;33(34):4161-4

5. Larson HJ, Jarrett C, Schulz WS, Chaudhuri M, Zhou Y, Dube E, Schuster M, MacDonald NE, Wilson R. Measuring vaccine hesitancy: the development of a survey tool. Vaccine. 2015 Aug 14;33(34):4165-75.

6. Larson HJ, Cooper LZ, Eskola J, Katz SL, Ratzan S. Addressing the vaccine confidence gap. The Lancet. 2011;378:526535.

7. Quinn SC, Parmer J, Freimuth VS, Hilyard KM, Musa D, Kim KH. Exploring 
communication, trust in government, and vaccination intention later in the 2009 H1N1 pandemic: results of a national survey. Biosecur Bioterror. 2013;11(2):96-106.

8. Barello S, Nania T, Dellafiore F, Graffigna G, Caruso R. 'Vaccine hesitancy' among university students in Italy during the COVID-19 pandemic. Eur $J$ Epidemiol. 2020;35(8):781-783.

9. Peretti-Watel P, Seror V, Cortaredona S, et al. A future vaccination campaign against COVID-19 at risk of vaccine hesitancy and politicisation. Lancet Infect Dis. 2020;20(7): 769-770.

10. İkiışık H, Sezerol MA, Taşçı Y, Maral I. COVID-19 Vaccine Hesitancy: A Community-Based Research in Turkey. International Journal of Clinical Practice. 2021 May 11:e14336.

How to cite this article: Keerthana S, Kamble $\mathrm{M}$, Khare $\mathrm{N}$ et.al. A study on COVID-19 vaccine hesitancy in Bhopal. Int $J$ Health Sci Res. 2022; 12(1): 111-116. DOI: https://doi. org/10.52403/ijhsr.20220116 